\title{
Evolution of Abscisic Acid Signaling Module and Its Perception
}

\author{
Yufei Sun ${ }^{1}$, Oded Pri-Tal ${ }^{1}$, Daphna Michaeli ${ }^{2}$ and Assaf Mosquna ${ }^{1 *}$ \\ 1 The Robert H. Smith Institute of Plant Sciences and Genetics in Agriculture, The Hebrew University of Jerusalem, Rehovot, \\ Israel, ${ }^{2}$ Tel Hai Rodman College, Upper Galilee, Israel
}

We hereby review the perception and responses to the stress hormone Abscisic acid (ABA), along the trajectory of 500M years of plant evolution, whose understanding may resolve how plants acquired this signaling pathway essential for the colonization of land. ABA levels rise in response to abiotic stresses, coordinating physiological and metabolic responses, helping plants survive stressful environments. In land plants, ABA signaling cascade leads to growth arrest and large-scale changes in transcript levels, required for coping with environmental stressors. This response is regulated by a PYRABACTIN RESISTANCE 1-like (PYL)-PROTEIN PHOSPHATASE 2C (PP2C)-SNF1-RELATED

OPEN ACCESS

Edited by:

Yoichi Sakata,

Tokyo University of Agriculture,

Japan

Reviewed by:

Jorge Lozano-Juste,

Polytechnic University

of Valencia, Spain

Yong Hwa Cheong, Sunchon National University,

South Korea

*Correspondence:

Assaf Mosquna

assaf.mosquna@mail.huji.ac.il

Specialty section:

This article was submitted to

Plant Abiotic Stress,

a section of the journal

Frontiers in Plant Science

Received: 02 April 2020

Accepted: 08 June 2020

Published: 10 July 2020

Citation:

Sun Y, Pri-Tal O, Michaeli D and Mosquna A (2020) Evolution of Abscisic Acid Signaling Module and Its Perception. Front. Plant Sci. 11:934. doi: 10.3389/fpls.2020.00934 PROTEIN KINASE 2 (SnRK2) module, that initiates phosphor-activation of transcription factors and ion channels. The enzymatic portions of this module (phosphatase and kinase) are functionally conserved from streptophyte algae to angiosperms, whereas the regulatory component -the PYL receptors, putatively evolved in the common ancestor of Zygnematophyceae and embryophyte as a constitutive, ABA-independent protein, further evolving into a ligand-activated receptor at the embryophyta. This evolutionary process peaked with the appearance of the strictly ABA-dependent subfamily III stress-triggered angiosperms' dimeric PYL receptors. The emerging picture is that the ancestor of land plants and its predecessors synthesized ABA, as its biosynthetic pathway is conserved between ancestral and current day algae. Despite this ability, it was only the common ancestor of land plants which acquired the hormonal-modulation of PYL activity by ABA. This raises several

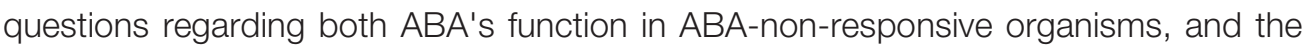
evolutionary aspects of the ABA signal transduction pathway.

\section{Keywords: abscisic acid, pyrabactin resistance 1 (PYR)/PYR1-like (PYL)/regulatory components of ABA receptor} (RCAR), plant signaling, PP2C group A, SnRK2, plant evolution

\section{INTRODUCTION}

Understanding the evolution of Abscisic acid (ABA) signaling may resolve the puzzle of how plants acquired a major stress signaling pathway that was essential for the colonization of land by ancestral plants. Early land plants, are believed to have been derived from a single common aquatic algal ancestor and had to cope with new challenges, unique to the terrestrial environment (see review by de Vries and Archibald, 2018). Desiccation tolerance was a key adaptive trait for aquatic organisms transitioning to terrestrial environment. This trait has been largely lost in vegetative tissues of trichophytes (see review by 
Cuming, 2019). Instead, angiosperm adaptation to land was dependent on the ability to regulate the intake and loss of water to the environment (see review by Anderegg, 2015). One major mean by which angiosperms maintain their water balance is the regulation of evapotranspiration via the stomata pores. A plant's daily transpiration rhythm is regulated by many internal and external factors, coordinating stomata aperture during its diurnal cycle. The production of the phytohormone ABA in case of an abiotic stress-overwrites transpiration rhythms and results in a rapid closure of the stomata (see review by Brodribb and McAdam, 2017). In the absence of ABA, as in the case of auxotrophic ABA mutants, the ability to close stomata in response to environmental cues is impaired, and as a result, the ability to endure harmful environments is compromised, ultimately deteriorating plant's growth and development (Koornneef et al., 1982; Taylor et al., 1988). Thus, ABA's regulation of land plant water balance is vital for a sessile plant, whose surroundings are in constant change.

The hormone ABA acts through a conserved signal transduction pathway. This pathway is comprised of a PYRABACTIN RESISTANCE 1-Like (PYL)-PROTEIN PHOSPHATASE 2C (PP2C) and SNF1-RELATED PROTEIN KINASE 2 (SnRK2). The binding of ABA to a soluble PYL protein triggers a conformational change that allows the receptors to bind and inhibit the PP2C that normally represses ABA signaling (Melcher et al., 2009; Miyazono et al., 2009; Nishimura et al., 2009; Park et al., 2009; Yin et al., 2009; Melcher et al., 2010; Peterson et al., 2010). This formation of PYL-ABA-PP2C complex, releases SnRK2 from the otherwise inhibitory complex with PP2C, initiating phosphorylation of transcription factors and ion channels, involved in ABA output responses (Fujii et al., 2009; Umezawa et al., 2009; see reviews by Hubbard et al., 2010; Weiner et al., 2010). This review focuses on the physiological and biochemical perception and responses to $\mathrm{ABA}$, along the trajectory of five hundred million years of plant evolution, from streptophyte algae to angiosperms.

\section{ABA “OUTPUT” RESPONSE IN ALGAE}

The presence of ABA has been confirmed in many chlorophytes and streptophyte algae species, yet the environment-induced synthesis of $\mathrm{ABA}$ was demonstrated solely in few aquatic algae species (Tietz and Kasprik, 1986; Hirsch et al., 1989; Hori et al., 2014). ABA biosynthesis in the chlorophytes Draparnaldia mutabilis and Dunahella parua is induced by salinity, whereas it is seasonally accumulated in the streptophyte algae Chara contraria (Sabbatini et al., 1987; Tietz et al., 1989; Hirsch et al., 1989). Despite the evidences of ABA biosynthesis in these aforementioned species, in the vast majority of explored algae, no such significant cellular or physiological function was documented (Hirsch et al., 1989; Tietz et al., 1989; Negin and Moshelion, 2016). This is true even in cases where algae were treated with high dosage of the phytohormone (Kobayashi et al., 1997; Nagao et al., 2008; Sulochana and Arumugam, 2016). Exceptions to note are the alterations of membrane properties of Nitella treated with ABA (Wanless et al., 1973; Ord et al., 1977) and the ABA inhibition of Chara oospores germination (Sederias and Colman, 2007). Despite these putative adaptive responses to $\mathrm{ABA}$, the effect on growth and other cellular functions in these studies were triggered by the application of high concentrations of ABA ranging from 40 to $500 \mu \mathrm{M}$, far from endogenous physiological hormone levels (Ullrich and Kunz, 1984; Saradhi et al., 2000; Yoshida et al., 2003; Yoshida et al., 2004). Thus, these extreme ABA concentrations, required to elicit such responses, are prone to attribute to toxicity rather than a putative activation of an ABA signaling cascade. Taken together, little evidence manifests a clear physiological function for $\mathrm{ABA}$ in chlorophyte and streptophyte algae, despite its obvious presence of in both algae phyla.

\section{ABA "OUTPUT" RESPONSES IN EARLY DIVERGENT LAND PLANTS (BRYOPHYTES, LYCOPHYTES, FERNS)}

The presence of endogenous $\mathrm{ABA}$, and the response to exogenous ABA application, are well described in bryophytes, but less so in lycophytes and ferns (see reviews by Hartung, 2010; Takezawa et al., 2011; Brodribb and McAdam, 2017). In bryophytes, ectopic $\mathrm{ABA}$ application and the genetic mimicking of ABA signaling affects various developmental processes. In liverworts, exogenous ABA inhibits gemma and thalli growth and the establishment and maintenance of gemma dormancy of Marchantia polymorpha (Tougane et al., 2010; Eklund et al., 2018). In mosses, ABA elicits protonemal morphological changes. For example, in Physcomitrella patens, ABA induces the formation of thickwalled spherical "brood cell", and it inhibits protonemal differentiation into "leafy" gametophores (Takezawa et al., 2011). The role of ABA in stress tolerance has also been demonstrated in bryophytes. In $M$. polymorpha, the application of ABA improved gemma survival rate following desiccation or freezing, hypothetically resulting from an ABA-induced accumulation of soluble sugars and intracellular rearrangement of vacuoles and chloroplasts (Pence et al., 2005; Hatanaka and Sugawara, 2010; Akter et al., 2014). In addition, the ABA-induced biosynthesis of bisbibenzyls was hypothesized to improve UV irradiation tolerance (Kageyama et al., 2015). Similarly, in a few moss species ( $P$. patens, Funaria hygrometrica, Atrichum undulatum and Ditrichum cornubicum) the application of ABA had a positive effect on tolerance to both desiccation and freezing (Takezawa et al., 2011). This adaptation to stress was putatively attributed to the accumulation of protective proteins such as the LATE EMBRYOGENESIS ABUNDANT (LEA), and enzymes associated with osmotic cellular adjustment (Khandelwal et al., 2010; Shinde et al., 2012; Ghosh et al., 2016). Thus, a cellular physiological response to $\mathrm{ABA}$, associated with the adaptation to abiotic stress is evidenced in the first plants habituating land.

The role of $\mathrm{ABA}$ in regulating stomata aperture, however, remains ambiguous in earlier divergent plants. Stomata was an "innovation" that facilitated plant terrestrial adaptation. It is 
generally present in most bryophyte plants except liverworts (see review by Chater et al., 2017). It is thought that the major function of bryophyte stomata was to allow spore capsule desiccation, as the stomata-deficient PpSMF1 (SPEECHLESS, MUTE and FAMA) mutant of $P$. patens retained water in its sporangia (Chater et al., 2016). Neither ectopic ABA application, nor the darkening of hornworts, triggered their stomata closure. However, hornworts' stomata did respond to reduction in water potential, emphasizing their potent responsiveness to environmental cues (Pressel et al., 2018). The application of $100 \mu \mathrm{M}$ of exogenous ABA did affect stomata aperture in both $P$. patens and F. hygrometrica, however, when ABA signaling was genetically blocked in $P$. patens, neither stomata aperture, nor spore capsule dehydration phenotypes, were reported, suggesting that the ectopically applied hormone levels might not mock on endogenous ABA titrations (Chater et al., 2011; Shinozawa et al., 2019). Taken together, further studies, involving genetic assays, could better clarify the inductive role of $\mathrm{ABA}$ in regulating stomata aperture in bryophytes.

In early vascular plants (lycophytes and ferns) there is an active debate regarding the regulation of stomatal aperture by ABA. Stomatal responses to ABA in these plants could be measured only under specific environmental conditions, suggesting a minor contribution of $\mathrm{ABA}$ to the regulation of their aperture (Ruszala et al., 2011; Soni et al., 2012; Hõrak et al., 2017). For example, Selaginella bryopteris stomata displayed no response to $\mathrm{ABA}$ in non-stress conditions, despite its response to $\mathrm{ABA}$ under the combination of high temperatures $\left(35^{\circ} \mathrm{C}\right)$ and highly elevated vapor pressure deficit (of 4.5kPa; Soni et al., 2012). A mild reduction in stomata conductance in Athyrium filix-femina and Dryopteris filix-mas was recorded when treated with $10 \mu \mathrm{M}$ foliar ABA spraying, however, the authors reported that this response was primarily dependent on cultivation methods (Hõrak et al., 2017). Additional stomatal conductance studies that were correlated with endogenous measurements of ABA levels showed that leaf hydraulics was the predominant factor that primarily regulated stomatal aperture while neither endogenous, nor exogenous ABA, triggered stomata closure in lycophytes and ferns (Brodribb and McAdam, 2011; McAdam and Brodribb, 2012; McAdam et al., 2016; Cardoso et al., 2019). Overall, due to the residual effect of ABA on stomata closure in the aforementioned studies, it seems that in bryophytes and early divergent vascular plants (lycophytes and ferns), stomatal regulation is primarily a hydraulics-driven process.

\section{THE PP2C-SNRK2 SIGNALING MODULE THROUGHOUT PLANT EVOLUTION}

The module of the PP2C-SnRK2 phosphatase-kinase is highly conserved throughout plant evolution, preceding the adoption of a regulatory role for the $\mathrm{ABA}$ molecule (Tougane et al.,
2010; Chater et al., 2011; Hauser et al., 2011; Ruszala et al., 2011; Komatsu et al., 2013; Lind et al., 2015; McAdam et al., 2016; Shinozawa et al., 2019). The cellular signaling of ABA in land plants initiates phosphorylation events mediated by a conserved family of SnRK2 kinases. Vascular plant SnRK2s are classified into three subclasses (Lind et al., 2015; McAdam et al., 2016). Subclass III SnRK2s are pivotal for ABA signaling in Arabidopsis, as in the absence of three such family members, there was an absolute shutdown of ABA signaling and response (Fujii and Zhu, 2009). The other SnRK2 subclasses play an important role in osmostress responses in Arabidopsis (Fujii et al., 2011). Streptophyte algae and bryophytes encode only subclass III SnRK2s, suggesting that the latter might be the founding members of the family, while the other two subclasses could have been a more recent adaptation of vascular plants (Umezawa et al., 2010; Lind et al., 2015).

An evolutionarily conserved function of subclass III SnRK2 in ABA signaling from streptophyta through angiosperms was demonstrated in multiple genetic studies (Chater et al., 2011; Ruszala et al., 2011; Shinozawa et al., 2019). In the moss $P$. patens, the deletion of $P p S n R K 2 A / P p O S T 1$ leads to a reduced stomatal response to ectopic $\mathrm{ABA}$, similar to a homologous single Arabidopsis snrk2.6/ost1 mutant (Chater et al., 2011). P. patens quadruple mutant $(s n r k 2 a / b / c / d)$ is ABA-insensitive, and it is brood cell development-deficient, lacking both ABA-induced gene expression and desiccation tolerance. Unfortunately, there was no data available regarding the sporophyte $\mathrm{ABA}$ response of this mutant, including its stomata response, nor its sporangium dehydration. This strong $P$. patens insensitive phenotype was similar to the Arabidopsis triple snrk2.2/2.3/2.6 mutant (Shinozawa et al., 2019), displaying complete ABA insensitivity. This conserved function of SnRK2 was further exemplified by algae/angiosperm-moss cross-species complementation (Shinozawa et al., 2019). The expression of either of the Arabidopsis SnRK2.6 gene or the semi-terrestrial alga Klebsormidium nitens KnOST1 gene complemented P. patens snrk2 quadruple mutants (Shinozawa et al., 2019). The expression of PpOST1 from $P$. patens or SmOST1 from the lycophyte Selaginella moellendorffi in Arabidopsis snrk2.6/ost1 mutant partially rescued stomata $\mathrm{ABA}$ insensitivity phenotype (Chater et al., 2011; Ruszala et al., 2011). Taken together, the plant SnRK2s functional conservation likely preceded land habituation.

Furthermore, the SnRK2 phosphorylation targets are also highly conserved throughout plant evolution. The S-type anion channel SLAC1 and ABRE/ABFs transcription factors are SnRK2 substrates in Arabidopsis (Furihata et al., 2006; Fujii et al., 2007; Geiger et al., 2009; Lee et al., 2009). SnRK2s from algae (K. nitens), liverworts ( $M$. polymorpha), moss (P. patens), lycophyte (S. moellendorffii) and fern (Ceratopteris richardii) could activate Arabidopsis SLAC1 in Xenopus laevis oocytes (Lind et al., 2015; McAdam et al., 2016). However, these SnRK2s cannot activate their native SLACs, suggesting that SnRK2-SLAC1 module for regulating stomata aperture emerged after divergence of ferns and seed plants 
(Lind et al., 2015; McAdam et al., 2016). SnRK2 ortholog from $K$. nitens, $M$. polymorpha and $P$. patens were capable of transducing ABA-induced gene expression via bZIP transcription factor ABF2 in Arabidopsis protoplasts (Lind et al., 2015). For detailed ABRE/ ABFs evolution see Cuming (2019). In addition, PpSnRK2s from $P$. patens and Arabidopsis SnRK2.6/OST1 phosphorylated in vitro the same ABA-responsive phosphopeptides (Amagai et al., 2018). Thus, not only is the kinase itself highly conserved, but also the cellular targets of class III SnRK2 are highly conserved, both from algae through angiosperms.

Both the positive and the negative regulatory proteins of the SnRK2 kinase are, too, conserved throughout land plant evolution (Lind et al., 2015; Saruhashi et al., 2015; Yasumura et al., 2015; Stevenson et al., 2016; Lin et al., 2020; Takahashi et al., 2020). Posttranslational modifications and protein-protein interactions are the two key regulation means of SnRK2 (Belin et al., 2006; Vlad et al., 2009; Soon et al., 2012; Saruhashi et al., 2015; Stevenson et al., 2016; Nguyen et al., 2019; Lin et al., 2020; Soma et al., 2020; Takahashi et al., 2020). The activation of Arabidopsis SnRK2s requires phosphorylation of key serine residues in kinase activation loop (Ser171 and Ser175 for AtSnRK2.6/OST1; Vlad et al., 2010; Soon et al., 2012). In the moss $P$. patens, the activation of SnRK2s is mediated by an ABA Non-Responsive/ABA Responsive Kinase/ Constitutive Triple-Response-1-Like (ANR/ARK/CTR1L) protein kinase, a member of B3 Raf-like kinases whose orthologues are conserved in streptophyte algae, but considered lost in vascular plants (Saruhashi et al., 2015; Yasumura et al., 2015; Stevenson et al., 2016; Shinozawa et al., 2019). Recent studies indicated that B2, B3 and B4 groups, are also of the Raf-like kinases family, and are essential for ABA-induced phosphorylation and activation of SnRK2s in Arabidopsis (Lin et al., 2020; Takahashi et al., 2020). Thus, this regulation by post-translational modification by Raf-like kinases is too, likely conserved from the common ancestor of algae to land plants.

Functional conservation is also the case for the negative PP2C regulators of SnRK2. In Arabidopsis, PP2Cs interacts with SnRK2s and inhibits the kinase activity as it dephosphorylates key serine residues in the kinase activation loop, and physically blocking the kinase catalytic site (Belin et al., 2006; Vlad et al., 2009; Soon et al., 2012). In angiosperms, group A PP2C contains multi-genes with redundant function (Leung et al., 1994; Meyer et al., 1994; Leung et al., 1997; Rodriguez et al., 1998; Saez et al., 2004; Schweighofer et al., 2004; Xue et al., 2008; Zhang et al., 2018; Fujioka et al., 2019). High-order of loss-of-function Arabidopsis mutant of PP2C displays an increase of ABA sensitivity, and partially constitutive ABA response (Saez et al., 2006; Rubio et al., 2009). Similarly, in the moss, two group A PP2Cs are encoded by $P$. Patens genome, and the disruption of $P p A B I 1 A$ gene results in up-regulation of $\mathrm{ABA}$-induced gene expression and enhanced freezing tolerance (Komatsu et al., 2009). The double mutant ppabila/b plant shows constitutive "brood cell" phenotype, a global activation of ABA-induced gene expression, and an increase in general protein phosphorylation, indicative of unchecked SnRK2 activity (Komatsu et al., 2013; Amagai et al., 2018). Overexpression of MpABI1 in $M$. polymorpha and $P$. patens resulted in an inhibition of ABAinduced gene expression and reduction of sensitivity of ABAinduced morphological changes (Tougane et al., 2010; Eklund et al., 2018). Moreover, moss and liverwort PP2C phosphatases inhibited SnRK2 activation of Arabidopsis SLAC1 expressed in Xenopus oocyte (Lind et al., 2015). Albeit all genomes of organisms from the green lineage (Chloroplastida) encode group A PP2Cs (Hauser et al., 2011), little is known about the biochemical interactions of these proteins with SnRK2s in algae. Taken together, these data suggest that $\mathrm{PP} 2 \mathrm{C}-\mathrm{SnRK} 2$ regulation module is conserved, possibly since the last common ancestor of streptophytes. As aforementioned, since algae do not activate signaling responses to $\mathrm{ABA}$ but they do actively transduce downstream signaling components homologous to higher plants', it is likely that the function of SnRK2, its regulatory components, and its cellular targets, preceded that of ABA signaling.

\section{THE EVOLUTION OF ABA RECEPTORS IN LAND PLANTS}

The regulatory unit controlling the aforementioned SnRK2-PP2C module is the most recent evolutionarily among the apex of ABAsignaling-transducing apparatuses. All land plants comprise ABA receptors whose function is largely conserved (Park et al., 2009; Ma et al., 2009; Gonzalez-Guzman et al., 2014; He et al., 2014; PriTal et al., 2017; Mega et al., 2019; Kai et al., 2019). Biochemically, ABA is perceived by a family of Steroidogenic Acute Regulatory Transfer (START)-domain protein receptor called PYRABACTIN RESISTANCE 1/PYR1-LIKE/REGULATORY COMPONENTS OF ABA RECEPTOR (PYR/PYL/RCAR) (Ma et al., 2009; Park et al., 2009). Structure studies reveal a "gate-latch-lock" mechanism that regulate receptor activity: ABA receptors have an open ligand-binding pocket, flanked by two mobile $\beta$-loops: the gate and latch. The binding of ABA in the pocket induces a closure of the gate loop and forms a surface that enables the docking of the $\mathrm{PP} 2 \mathrm{C}$ co-receptor. A highly conserved tryptophan of PP2C inserts into the "ABA pocket" to further stabilize the PYL-ABA-PP2C ternary complex (Melcher et al., 2009; Miyazono et al., 2009; Yin et al., 2009; Moreno-Alvero et al., 2017). This formation of the ternary complex releases SnRK2 from PP2C inhibition as the PYL and SnRK2 compete on the same PP2C interface (Soon et al., 2012).

In angiosperms, PYL proteins are clustered into three subfamilies, which differ in their affinity to ABA, and in their oligomeric state, each comprised of multiple genes with a partially redundant function. Subfamily III receptor forms a homodimer, whereas subfamily I and II receptors are monomers (Miyazono et al., 2009; Nishimura et al., 2009; Santiago et al., 2009; Szostkiewicz et al., 2010; Hao et al., 2011; He et al., 2014). Mutations resulting in monomer conformation increase the receptor's affinity to ABA and to the PP2C (Dupeux et al., 2011; Hao et al., 2011). Monomeric $\mathrm{ABA}$ receptors, in comparison to dimeric receptors, require lower ABA concentration to elicit PP2C inhibition (Okamoto et al., 2013; 
Gonzalez-Guzman et al., 2014; Pri-Tal et al., 2017; Mega et al., 2019). Based on in vitro data, some monomeric receptors have "basal activity", thereby able to interact and inhibit PP2C activity in the absence of ABA (Hao et al., 2011; Mosquna et al., 2011; Sun et al., 2019). In contrast, dimeric receptors have negligible basal activity, as ABA is required for dimer dissociation (Dupeux et al., 2011; Hao et al., 2011).

Bryophyte receptors are clustered distinctly from vascular plants according to phylogenetic analyses (Weng et al., 2016; Sun et al., 2019). Among vascular plant receptors, subfamily I is phylogenetically closer to that of bryophytes, and subfamily III likely diverged later, as it is unique to angiosperm (Hauser et al., 2011; Weng et al., 2016; Sun et al., 2019). It has been shown that land plant PYL receptors have evolutionarily conserved function (Bowman et al., 2017; Jahan et al., 2019; Shinozawa et al., 2019; Sun et al., 2019). In liverworts, single receptor MpPYL1 knock-out $M$. polymorpha mutant abolished ABA-induced growth inhibition and gene expression (Jahan et al., 2019). The conserved function of MpPYL1 was further confirmed by ABA binding ability, receptor-mediated PP2C inhibition, the activation of ABA-induced gene expression, and the cross-species complementation of Arabidopsis ABA-related mutants compromise in either of biosynthetic-pathways or PYL genes (Bowman et al., 2017; Jahan et al., 2019; Sun et al., 2019). Similarly, ABA receptors from the moss $P$. Patens and the lycophyte S. moellendorffi displayed both PP2C inhibition and activation of ABA-induced gene expression (Shinozawa et al., 2019; Sun et al., 2019). As the essence of the function of the receptor is the binding to its target, the PP2C interface, the conservation of these targets might themselves have dictated receptor functional conservation, as the SnRK2 and the receptor compete on the very same interface in $\mathrm{PP} 2 \mathrm{C}$.

\section{THE ALGAL ORIGIN OF ABA RECEPTORS}

The majority of algae genomes do not encode PYL-like proteins, but few species comprise PYL-like proteins, whose conserved basal, ABA-independent PP2C inhibition activity, suggests that the regulation of $\mathrm{PP} 2 \mathrm{C}$ activity might be the ancestral function of the PYL proteins (Sun et al., 2019). Recent genomic and transcriptomic studies demonstrated that some Zygnematophyceae algae genome encode PYL homologous proteins (de Vries et al., 2018; Cheng et al., 2019). Protein sequence analysis of these Zygnematophyceae PYLs revealed amino acid differences in ABA-binding residues, otherwise conserved in bona fide $\mathrm{ABA}$ receptors (Sun et al., 2019). Biochemical and genetic complementation assays, confirmed that Zygnema circumcarinatum PYL-like protein (ZcPYL8) can elicit ABA signaling in Arabidopsis as it possesses the ability to inhibit PP2C. Further analysis demonstrated that this protein has basal, ABA-independent PP2C inhibition activity, and it could not bind ABA (Sun et al., 2019). Thus, the analysis of the algal PYL indicate that
ABA hormonal modulation via ligand activation was acquired after the divergence of the ancestor of streptophyte algae from the common ancestor of land plants (Sun et al., 2019).

Studies describe two intertwined trends in the evolution of the $\mathrm{ABA}$ receptors: the rise in gene number due to the increase in genetic complexity; and the reduction in receptor $\mathrm{ABA}$ independent basal activity (Sun et al., 2019). We hereby focus on the reduction in receptor basal activity as former reviews by Umezawa et al. (2010) and Hauser et al. (2011) explored the topic of the increase in genetic complexity. The analysis of ABAindependent receptor inhibition of PP2C by PYLs encoded by early divergent plants, suggests a reduction in receptor ABA-independent, constitutive basal activity, in favor of ABAdependent activity. For example, basal activity of $M$. polymorpha MPPYL1 was around 50\% phosphatase inhibition in the absence of ABA. In comparison, three out of four receptors of $S$. moellendorffi had only $15-30 \%$ such basal activity, while the fourth SmPYL2 was fully ABA-dependent (Sun et al., 2019). This evolutionary process peaked with the appearance of the strictly ABA-dependent subfamily III dimeric receptors, which are limited to later divergent angiosperms. Lower basal activity provides a broader range of response, and so is the contrary: high basal activity masks the fine-tuned ABA-triggered response. The reduction of ABA-independent basal constitutive activity, alongside the appearance of the dimeric receptors that dominate the response in angiosperms, suggests that a dampening of the basal activity of the receptors was a driving force for the evolution of ABA responsiveness in land plant PYLs (Sun et al., 2019). Thus, in angiosperms, dimeric PYL receptors have evolved, allowing both "finer-tuning" response to variable levels of ABA, and dominating the adaptive stress response of ABA (Park et al., 2009; Okamoto et al., 2013; Pri-Tal et al., 2017; Vaidya et al., 2017; Vaidya et al., 2019).

\section{CONCLUSIONS AND OPEN QUESTIONS: THE EVOLUTIONARY COURSE OF ABA SIGNALING MODULE}

The collective data from recent years allow us to draw a putative picture of plant ABA signaling evolution (Figure 1). It is likely that the common ancestor of Zygnematophyceae and embryophytes possessed a PP2C-SnRK2 module that was regulated by a PYL-like protein (also reviewed by Fürst-Jansen et al., 2020). It is still unknown how these organisms regulated the activity of the PYLlike proteins, whether it was by transcriptional, translational or post-translational modifications, or possibly, by allosteric modulation of a yet unidentified hypothetical small molecule. The origin of the PYL proteins is also currently unknown, however, one hypothesis suggests that this ancestral START domain protein was obtained from soil bacteria via horizontal gene transfer (Cheng et al., 2019).

The ancestor of land plants and his predecessors synthesized $\mathrm{ABA}$, as its biosynthetic pathway is conserved between 


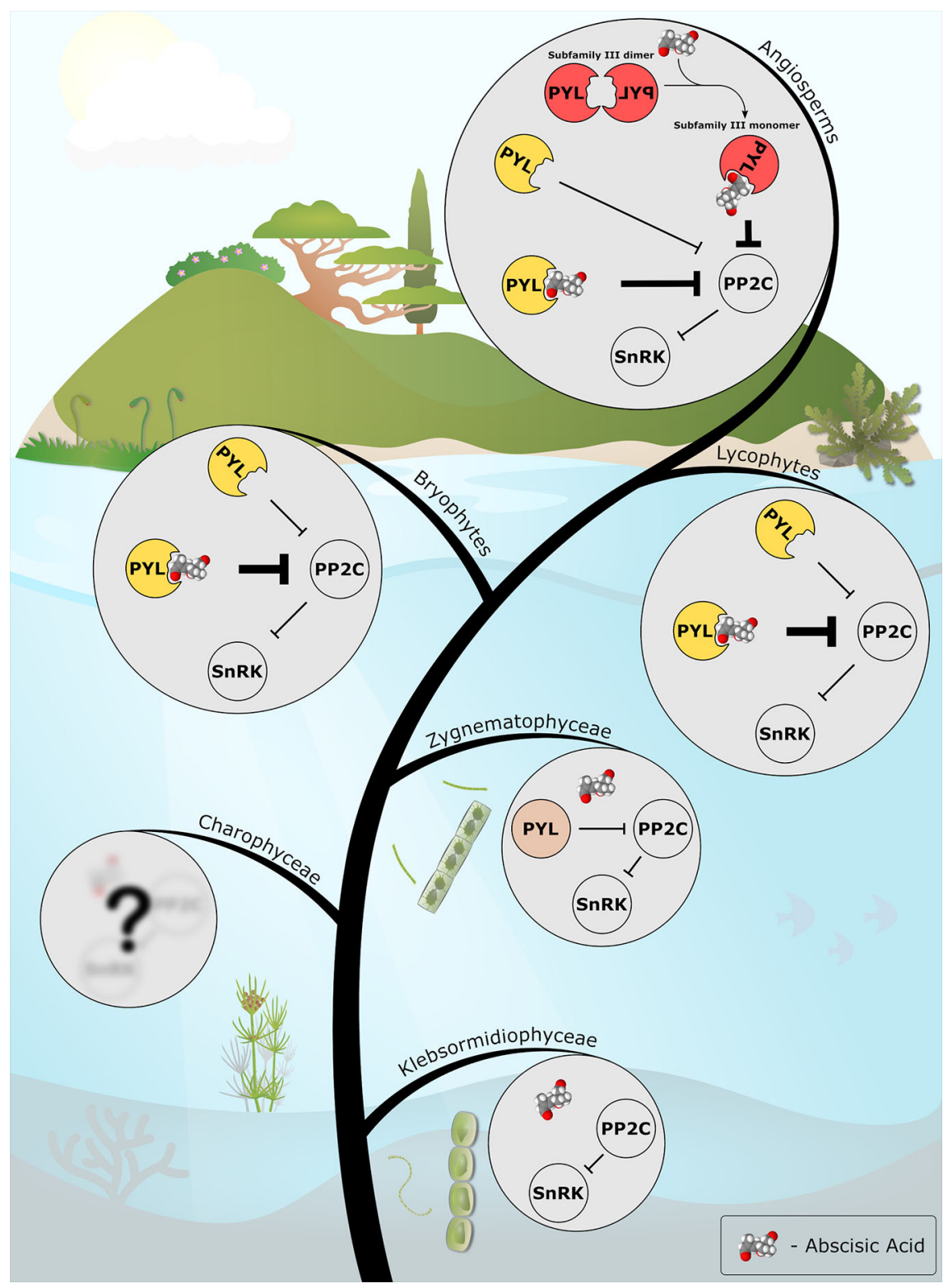

FIGURE 1 | The emerging evolutionary scenario of ABA signaling as described in this review. ABA biosynthesis and PP2C-SnRK2 signaling modules are present in the streptophyte algae (e.g. Klebsormidiophyceae). A PYL protein with only basal, ABA-independent, PP2C-inhibition activity (in light brown) evolved in the common ancestor of Zygnematophyceae and land plants. Along the course of evolution, the PYL protein of the last common ancestor of land plants (in yellow) gained the ABA-dependent activity, thus recruited ABA into the preexisting signaling cascade. In angiosperms, the appearance of a new subfamily of dimeric PYLs (in red) added another layer of regulation, facilitating ABA-mediated fine-tuning of abiotic stress signaling in plants. ABA molecule is presented as a Van der Waals spheres model. The model was generated with Jmol: an open-source Java viewer for chemical structures in 3D. http://www.jmol.org/.

ancestral and current algae (Hauser et al., 2011; de Vries et al., 2018). Despite this ability to produce ABA, it was only the common ancestor of land plants whom acquired the hormonally modulation of PYL activity by ABA (Sun et al., 2019). This raises several questions regarding $A B A$ 's function in ABA-non-responsive organisms, such as modern day algae, and regarding evolutionary aspects of the $\mathrm{ABA}$ signal transduction pathway, such as what made $A B A$ in particular a successful stress transducer?

\section{AUTHOR CONTRIBUTIONS}

YS, DM, and AM drafted the manuscript. OP-T contributed to the graphics.

\section{FUNDING}

The Israel Science Foundation (No. 661/18) was the only funding source. 


\section{REFERENCES}

Akter, K., Kato, M., Sato, Y., Kaneko, Y., and Takezawa, D. (2014). Abscisic acidinduced rearrangement of intracellular structures associated with freezing and desiccation stress tolerance in the liverwort Marchantia polymorpha. J. Plant Physiol. 171, 1334-1343. doi: 10.1016/j.jplph.2014.05.004

Amagai, A., Honda, Y., Ishikawa, S., Hara, Y., Kuwamura, M., Shinozawa, A., et al. (2018). Phosphoproteomic profiling reveals ABA-responsive phosphosignaling pathways in Physcomitrella patens. Plant J. 94, 699-708. doi: 10.1111/tpj.13891

Anderegg, W. R. (2015). Spatial and temporal variation in plant hydraulic traits and their relevance for climate change impacts on vegetation. New Phytol. 205, 1008-1014. doi: 10.1111/nph.12907

Belin, C., de Franco, P. O., Bourbousse, C., Chaignepain, S., Schmitter, J. M., Vavasseur, A., et al. (2006). Identification of features regulating OST1 kinase activity and OST1 function in guard cells. Plant Physiol. 141, 1316-1327. doi: 10.1104/pp.106.079327

Bowman, J. L., Kohchi, T., Yamato, K. T., Jenkins, J., Shu, S., Ishizaki, K., et al. (2017). Insights into land plant evolution garnered from the Marchantia polymorpha genome. Cell 171, 287-304 e215. doi: 10.1016/j.cell.2017.09.030

Brodribb, T. J., and McAdam, S. A. (2011). Passive origins of stomatal control in vascular plants. Science 331, 582-585. doi: 10.1126/science.1197985

Brodribb, T. J., and McAdam, S. A. M. (2017). Evolution of the stomatal regulation of plant water content. Plant Physiol. 174, 639-649. doi: 10.1104/pp.17.00078

Cardoso, A. A., Randall, J. M., and McAdam, S. A. (2019). Hydraulics regulate stomatal responses to changes in leaf water status in the fern Athyrium filixfemina. Plant Physiol. 179, 533-543. doi: 10.1104/pp.18.01412

Chater, C., Kamisugi, Y., Movahedi, M., Fleming, A., Cuming, A. C., Gray, J. E., et al. (2011). Regulatory mechanism controlling stomatal behavior conserved across 400 million years of land plant evolution. Curr. Biol. 21, 1025-1029. doi: 10.1016/j.cub.2011.04.032

Chater, C. C., Caine, R. S., Tomek, M., Wallace, S., Kamisugi, Y., Cuming, A. C., et al. (2016). Origin and function of stomata in the moss Physcomitrella patens. Nat. Plants 2, 1-7. doi: 10.1038/nplants.2016.179

Chater, C. C., Caine, R. S., Fleming, A. J., and Gray, J. E. (2017). Origins and evolution of stomatal development. Plant Physiol. 174, 624-638. doi: 10.1104/ pp.17.00183

Cheng, S., Xian, W., Fu, Y., Marin, B., Keller, J., Wu, T., et al. (2019). Genomes of subaerial Zygnematophyceae provide insights into land plant evolution. Cell 179, 1057-1067 e1014. doi: 10.1016/j.cell.2019.10.019

Cuming, A. C. (2019). Evolution of ABA signaling pathways. Abscisic Acid Plants 93, 281-313. doi: 10.1016/bs.abr.2019.06.003

de Vries, J., and Archibald, J. M. (2018). Plant evolution: landmarks on the path to terrestrial life. New Phytol. 217, 1428-1434. doi: 10.1111/nph.14975

de Vries, J., Curtis, B. A., Gould, S. B., and Archibald, J. M. (2018). Embryophyte stress signaling evolved in the algal progenitors of land plants. Proc. Natl. Acad. Sci. U. S. A. 115, E3471-E3480. doi: 10.1073/pnas.1719230115

Dupeux, F., Santiago, J., Betz, K., Twycross, J., Park, S. Y., Rodriguez, L., et al. (2011). A thermodynamic switch modulates abscisic acid receptor sensitivity. EMBO J. 30, 4171-4184. doi: 10.1038/emboj.2011.294

Eklund, D. M., Kanei, M., Flores-Sandoval, E., Ishizaki, K., Nishihama, R., Kohchi, T., et al. (2018). An evolutionarily conserved abscisic acid signaling pathway regulates dormancy in the liverwort Marchantia polymorpha. Curr. Biol. 28, 3691-3699. e3693. doi: 10.1016/j.cub.2018.10.018

Fürst-Jansen, J. M., de Vries, S., and Vries, J. D. (2020). Evo-physio: on stress responses and the earliest land plants. J. Exp. Bot. 71, 3254-3269. doi: 10.1093/ jxb/eraa007

Fujii, H., and Zhu, J. K. (2009). Arabidopsis mutant deficient in 3 abscisic acid-activated protein kinases reveals critical roles in growth, reproduction, and stress. Proc. Natl. Acad. Sci. U. S. A. 106, 8380-8385. doi: 10.1073/pnas.0903144106

Fujii, H., Verslues, P. E., and Zhu, J.-K. (2007). Identification of two protein kinases required for abscisic acid regulation of seed germination, root growth, and gene expression in Arabidopsis. Plant Cell 19, 485-494. doi: 10.1105/tpc.106.048538

Fujii, H., Chinnusamy, V., Rodrigues, A., Rubio, S., Antoni, R., Park, S. Y., et al. (2009). In vitro reconstitution of an abscisic acid signalling pathway. Nature 462, 660-664. doi: 10.1038/nature08599

Fujii, H., Verslues, P. E., and Zhu, J. K. (2011). Arabidopsis decuple mutant reveals the importance of SnRK2 kinases in osmotic stress responses in vivo. Proc. Natl. Acad. Sci. U. S. A. 108, 1717-1722. doi: 10.1073/pnas.1018367108
Fujioka, H., Samejima, H., Suzuki, H., Mizutani, M., Okamoto, M., and Sugimoto, Y. (2019). Aberrant protein phosphatase $2 \mathrm{C}$ leads to abscisic acid insensitivity and high transpiration in parasitic Striga. Nat. Plants 5, 258-262. doi: 10.1038/ s41477-019-0362-7

Furihata, T., Maruyama, K., Fujita, Y., Umezawa, T., Yoshida, R., Shinozaki, K., et al. (2006). Abscisic acid-dependent multisite phosphorylation regulates the activity of a transcription activator AREB1. Proc. Natl. Acad. Sci. U. S. A. 103, 1988-1993. doi: 10.1073/pnas.0505667103

Geiger, D., Scherzer, S., Mumm, P., Stange, A., Marten, I., Bauer, H., et al. (2009). Activity of guard cell anion channel SLAC1 is controlled by drought-stress signaling kinase-phosphatase pair. Proc. Natl. Acad. Sci. U. S. A. 106, 2142521430. doi: $10.1073 /$ pnas.0912021106

Ghosh, T. K., Kaneko, M., Akter, K., Murai, S., Komatsu, K., Ishizaki, K., et al. (2016). Abscisic acid-induced gene expression in the liverwort Marchantia polymorpha is mediated by evolutionarily conserved promoter elements. Physiol. Plant. 156, 407-420. doi: 10.1111/ppl.12385

Gonzalez-Guzman, M., Rodriguez, L., Lorenzo-Orts, L., Pons, C., SarrionPerdigones, A., Fernandez, M. A., et al. (2014). Tomato PYR/PYL/RCAR abscisic acid receptors show high expression in root, differential sensitivity to the abscisic acid agonist quinabactin, and the capability to enhance plant drought resistance. J. Exp. Bot. 65, 4451-4464. doi: 10.1093/jxb/eru219

Hõrak, H., Kollist, H., and Merilo, E. (2017). Fern stomatal responses to ABA and CO2 depend on species and growth conditions. Plant Physiol. 174, 672-679. doi: 10.1104/pp.17.00120

Hao, Q., Yin, P., Li, W., Wang, L., Yan, C., Lin, Z., et al. (2011). The molecular basis of ABA-independent inhibition of PP2Cs by a subclass of PYL proteins. Mol. Cell 42, 662-672. doi: 10.1016/j.molcel.2011.05.011

Hartung, W. (2010). The evolution of abscisic acid (ABA) and ABA function in lower plants, fungi and lichen. Funct. Plant Biol. 37, 806-812. doi: 10.1071/ FP10058

Hatanaka, R., and Sugawara, Y. (2010). Development of desiccation tolerance and vitrification by preculture treatment in suspension-cultured cells of the liverwort Marchantia polymorpha. Planta 231, 965-976. doi: 10.1007/ s00425-010-1101-5

Hauser, F., Waadt, R., and Schroeder, J. I. (2011). Evolution of abscisic acid synthesis and signaling mechanisms. Curr. Biol. 21, R346-R355. doi: 10.1016/ j.cub.2011.03.015

He, Y., Hao, Q., Li, W., Yan, C., Yan, N., and Yin, P. (2014). Identification and characterization of ABA receptors in Oryza sativa. PloS One 9, e95246. doi: 10.1371/journal.pone.0095246

Hirsch, R., Hartung, W., and Gimmler, H. (1989). Abscisic acid content of algae under stress. Bot. Acta 102, 326-334. doi: 10.1111/j.1438-8677.1989.tb00113.x

Hori, K., Maruyama, F., Fujisawa, T., Togashi, T., Yamamoto, N., Seo, M., et al. (2014). Klebsormidium flaccidum genome reveals primary factors for plant terrestrial adaptation. Nat. Commun. 5, 3978. doi: 10.1038/ncomms4978

Hubbard, K. E., Nishimura, N., Hitomi, K., Getzoff, E. D., and Schroeder, J. I. (2010). Early abscisic acid signal transduction mechanisms: newly discovered components and newly emerging questions. Genes Dev. 24, 1695-1708. doi: 10.1101/gad.1953910

Jahan, A., Komatsu, K., Wakida-Sekiya, M., Hiraide, M., Tanaka, K., Ohtake, R., et al. (2019). Archetypal roles of an abscisic acid receptor in drought and sugar responses in liverworts. Plant Physiol. 179, 317-328. doi: 10.1104/pp.18.00761

Kageyama, A., Ishizaki, K., Kohchi, T., Matsuura, H., and Takahashi, K. (2015). Abscisic acid induces biosynthesis of bisbibenzyls and tolerance to UV-C in the liverwort Marchantia polymorpha. Phytochemistry 117, 547-553. doi: 10.1016/ j.phytochem.2015.05.009

Kai, W., Wang, J., Liang, B., Fu, Y., Zheng, Y., Zhang, W., et al. (2019). PYL9 is involved in the regulation of $\mathrm{ABA}$ signaling during tomato fruit ripening. $J$. Exp. Bot. 70, 6305-6319. doi: 10.1093/jxb/erz396

Khandelwal, A., Cho, S. H., Marella, H., Sakata, Y., Perroud, P.-F., Pan, A., et al. (2010). Role of ABA and ABI3 in desiccation tolerance. Science 327, 546-546. doi: $10.1126 /$ science. 1183672

Kobayashi, M., Hirai, N., Kurimura, Y., Ohigashi, H., and Tsuji, Y. (1997). Abscisic acid-dependent algal morphogenesis in the unicellular green alga Haematococcus pluvialis. Plant Growth Regul. 22, 79-85. doi: 10.1023/A:1005862809711

Komatsu, K., Nishikawa, Y., Ohtsuka, T., Taji, T., Quatrano, R. S., Tanaka, S., et al. (2009). Functional analyses of the ABI1-related protein phosphatase type $2 \mathrm{C}$ reveal evolutionarily conserved regulation of abscisic acid signaling between 
Arabidopsis and the moss Physcomitrella patens. Plant Mol. Biol. 70, 327-340. doi: 10.1007/s11103-009-9476-z

Komatsu, K., Suzuki, N., Kuwamura, M., Nishikawa, Y., Nakatani, M., Ohtawa, H., et al. (2013). Group A PP2Cs evolved in land plants as key regulators of intrinsic desiccation tolerance. Nat. Commun. 4, 2219. doi: 10.1038/ ncomms 3219

Koornneef, M., Jorna, M., Brinkhorst-Van der Swan, D., and Karssen, C. (1982). The isolation of abscisic acid (ABA) deficient mutants by selection of induced revertants in non-germinating gibberellin sensitive lines of Arabidopsis thaliana (L.) Heynh. Theor. Appl. Genet. 61, 385-393. doi: 10.1007/BF00272861

Lee, S. C., Lan, W., Buchanan, B. B., and Luan, S. (2009). A protein kinasephosphatase pair interacts with an ion channel to regulate ABA signaling in plant guard cells. Proc. Natl. Acad. Sci. U. S. A. 106, 21419-21424. doi: 10.1073/ pnas.0910601106

Leung, J., Bouvier-Durand, M., Morris, P. C., Guerrier, D., Chefdor, F., and Giraudat, J. (1994). Arabidopsis ABA response gene ABI1: features of a calcium-modulated protein phosphatase. Science 264, 1448-1452. doi: 10.1126/science.7910981

Leung, J., Merlot, S., and Giraudat, J. (1997). The Arabidopsis ABSCISIC ACIDINSENSITIVE2 (ABI2) and ABI1 genes encode homologous protein phosphatases 2C involved in abscisic acid signal transduction. Plant Cell 9, 759-771. doi: 10.1105/tpc.9.5.759

Lin, Z., Li, Y., Zhang, Z., Liu, X., Hsu, C. C., Du, Y., et al. (2020). A RAF-SnRK2 kinase cascade mediates early osmotic stress signaling in higher plants. Nat. Commun. 11, 613. doi: 10.1038/s41467-020-14477-9

Lind, C., Dreyer, I., López-Sanjurjo, E. J., von Meyer, K., Ishizaki, K., Kohchi, T., et al. (2015). Stomatal guard cells co-opted an ancient ABA-dependent desiccation survival system to regulate stomatal closure. Curr. Biol. 25, 928935. doi: 10.1016/j.cub.2015.01.067

Ma, Y., Szostkiewicz, I., Korte, A., Moes, D., Yang, Y., Christmann, A., et al. (2009). Regulators of PP2C phosphatase activity function as abscisic acid sensors. Science 324, 1064-1068. doi: 10.1126/science. 1172408

McAdam, S. A., and Brodribb, T. J. (2012). Fern and lycophyte guard cells do not respond to endogenous abscisic acid. Plant Cell 24, 1510-1521. doi: 10.1105/ tpc.112.096404

McAdam, S. A., Brodribb, T. J., Banks, J. A., Hedrich, R., Atallah, N. M., Cai, C., et al. (2016). Abscisic acid controlled sex before transpiration in vascular plants. Proc. Natl. Acad. Sci. U. S. A. 113, 12862-12867. doi: 10.1073/pnas.1606614113

Mega, R., Abe, F., Kim, J. S., Tsuboi, Y., Tanaka, K., Kobayashi, H., et al. (2019). Tuning water-use efficiency and drought tolerance in wheat using abscisic acid receptors. Nat. Plants 5, 153-159. doi: 10.1038/s41477-019-0361-8

Melcher, K., Ng, L. M., Zhou, X. E., Soon, F. F., Xu, Y., Suino-Powell, K. M., et al. (2009). A gate-latch-lock mechanism for hormone signalling by abscisic acid receptors. Nature 462, 602-608. doi: 10.1038/nature08613

Melcher, K., Xu, Y., Ng, L. M., Zhou, X. E., Soon, F. F., Chinnusamy, V., et al. (2010). Identification and mechanism of ABA receptor antagonism. Nat. Struct. Mol. Biol. 17, 1102-1108. doi: 10.1038/nsmb.1887

Meyer, K., Leube, M. P., and Grill, E. (1994). A protein phosphatase 2C involved in ABA signal transduction in Arabidopsis thaliana. Science 264, 1452-1455. doi: $10.1126 /$ science. 8197457

Miyazono, K., Miyakawa, T., Sawano, Y., Kubota, K., Kang, H. J., Asano, A., et al. (2009). Structural basis of abscisic acid signalling. Nature 462, 609-614. doi: 10.1038/nature 08583

Moreno-Alvero, M., Yunta, C., Gonzalez-Guzman, M., Lozano-Juste, J., Benavente, L. J., Arbona, V., et al. (2017). Structure of ligand-bound intermediates of crop ABA receptors highlights PP2C as necessary ABA coreceptor. Mol. Plant 10, 1250-1253. doi: 10.1016/j.molp.2017.07.004

Mosquna, A., Peterson, F. C., Park, S. Y., Lozano-Juste, J., Volkman, B. F., and Cutler, S. R. (2011). Potent and selective activation of abscisic acid receptors in vivo by mutational stabilization of their agonist-bound conformation. Proc. Natl. Acad. Sci. U. S. A. 108, 20838-20843. doi: 10.1073/pnas.1112838108

Nagao, M., Matsui, K., and Uemura, M. (2008). Klebsormidium flaccidum, a charophycean green alga, exhibits cold acclimation that is closely associated with compatible solute accumulation and ultrastructural changes. Plant Cell Environ. 31, 872-885. doi: 10.1111/j.1365-3040.2008.01804.x

Negin, B., and Moshelion, M. (2016). The evolution of the role of ABA in the regulation of water-use efficiency: From biochemical mechanisms to stomatal conductance. Plant Sci. 251, 82-89. doi: 10.1016/j.plantsci.2016.05.007
Nguyen, Q. T. C., Lee, S.-J., Choi, S.-W., Na, Y.-J., Song, M.-R., Hoang, Q. T. N., et al. (2019). Arabidopsis Raf-like kinase raf10 is a regulatory component of core ABA signaling. Mol. Cells 42, 646-660. doi: 10.14348/molcells.2019.0173

Nishimura, N., Hitomi, K., Arvai, A. S., Rambo, R. P., Hitomi, C., Cutler, S. R., et al. (2009). Structural mechanism of abscisic acid binding and signaling by dimeric PYR1. Science 326, 1373-1379. doi: 10.1126/science.1181829

Okamoto, M., Peterson, F. C., Defries, A., Park, S. Y., Endo, A., Nambara, E., et al. (2013). Activation of dimeric ABA receptors elicits guard cell closure, ABAregulated gene expression, and drought tolerance. Proc. Natl. Acad. Sci. U. S. A. 110, 12132-12137. doi: 10.1073/pnas.1305919110

Ord, G. S. G., Cameron, I., and Fensom, D. (1977). The effect of pH and ABA on the hydraulic conductivity of Nitella membranes. Can. J. Bot. 55, 1-4. doi: 10.1139/b77-001

Park, S. Y., Fung, P., Nishimura, N., Jensen, D. R., Fujii, H., Zhao, Y., et al. (2009). Abscisic acid inhibits type $2 \mathrm{C}$ protein phosphatases via the PYR/PYL family of START proteins. Science 324, 1068-1071. doi: 10.1126/science.1173041

Pence, V. C., Dunford, S. S., and Redella, S. (2005). Differential effects of abscisic acid on desiccation tolerance and carbohydrates in three species of liverworts. J. Plant Physiol. 162, 1331-1337. doi: 10.1016/j.jplph.2005.02.002

Peterson, F. C., Burgie, E. S., Park, S. Y., Jensen, D. R., Weiner, J. J., Bingman, C. A., et al. (2010). Structural basis for selective activation of ABA receptors. Nat. Struct. Mol. Biol. 17, 1109-1113. doi: 10.1038/nsmb.1898

Pressel, S., Renzaglia, K. S., Clymo, R. S., and Duckett, J. G. (2018). Hornwort stomata do not respond actively to exogenous and environmental cues. Ann. Bot. 122, 45-57. doi: 10.1093/aob/mcy045

Pri-Tal, O., Shaar-Moshe, L., Wiseglass, G., Peleg, Z., and Mosquna, A. (2017). Non-redundant functions of the dimeric ABA receptor BdPYL1 in the grass Brachypodium. Plant J. 92, 774-786. doi: 10.1111/tpj.13714

Rodriguez, P. L., Leube, M. P., and Grill, E. (1998). Molecular cloning in Arabidopsis thaliana of a new protein phosphatase 2C (PP2C) with homology to ABI1 and ABI2. Plant Mol. Biol. 38, 879-883. doi: 10.1023/ A:1006012218704

Rubio, S., Rodrigues, A., Saez, A., Dizon, M. B., Galle, A., Kim, T. H., et al. (2009). Triple loss of function of protein phosphatases type $2 \mathrm{C}$ leads to partial constitutive response to endogenous abscisic acid. Plant Physiol. 150, 13451355. doi: 10.1104/pp.109.137174

Ruszala, E. M., Beerling, D. J., Franks, P. J., Chater, C., Casson, S. A., Gray, J. E., et al. (2011). Land plants acquired active stomatal control early in their evolutionary history. Curr. Biol. 21, 1030-1035. doi: 10.1016/j.cub.2011.04.044

Sabbatini, M., Argüello, J., Fernandez, O., and Bottini, R. (1987). Dormancy and growth-inhibitor levels in oospores of Chara contraria A. Braun ex Kütz.(Charophyta). Aquat. Bot. 28 (2), 189-194. doi: 10.1016/0304-3770(87) 90040-4

Saez, A., Apostolova, N., Gonzalez-Guzman, M., Gonzalez-Garcia, M. P., Nicolas, C., Lorenzo, O., et al. (2004). Gain-of-function and loss-of-function phenotypes of the protein phosphatase $2 \mathrm{C} \mathrm{HAB1}$ reveal its role as a negative regulator of abscisic acid signaling. Plant J. 37, 354-369. doi: 10.1046/j.1365-313X.2003.01966.x

Saez, A., Robert, N., Maktabi, M. H., Schroeder, J. I., Serrano, R., and Rodriguez, P. L. (2006). Enhancement of abscisic acid sensitivity and reduction of water consumption in Arabidopsis by combined inactivation of the protein phosphatases type 2C ABI1 and HAB1. Plant Physiol. 141, 1389-1399. doi: 10.1104/pp.106.081018

Santiago, J., Dupeux, F., Round, A., Antoni, R., Park, S. Y., Jamin, M., et al. (2009). The abscisic acid receptor PYR1 in complex with abscisic acid. Nature 462, 665-668. doi: 10.1038/nature08591

Saradhi, P. P., Suzuki, I., Katoh, A., Sakamoto, A., Sharmila, P., Shi, D. J., et al. (2000). Protection against the photo-induced inactivation of the photosystem II complex by abscisic acid. Plant Cell Environ. 23, 711-718. doi: 10.1046/ j.1365-3040.2000.00579.x

Saruhashi, M., Ghosh, T. K., Arai, K., Ishizaki, Y., Hagiwara, K., Komatsu, K., et al. (2015). Plant Raf-like kinase integrates abscisic acid and hyperosmotic stress signaling upstream of SNF1-related protein kinase2. Proc. Natl. Acad. Sci. U. S. A. 112, E6388-E6396. doi: 10.1073/pnas.1511238112

Schweighofer, A., Hirt, H., and Meskiene, I. (2004). Plant PP2C phosphatases: emerging functions in stress signaling. Trends Plant Sci. 9, 236-243. doi: 10.1016/j.tplants.2004.03.007

Sederias, J., and Colman, B. (2007). The interaction of light and low temperature on breaking the dormancy of Chara vulgaris oospores. Aquat. Bot. 87, 229-234. doi: 10.1016/j.aquabot.2007.06.008 
Shinde, S., Nurul Islam, M., and Ng, C. K. Y. (2012). Dehydration stress-induced oscillations in LEA protein transcripts involves abscisic acid in the moss, Physcomitrella patens. New Phytol. 195, 321-328. doi: 10.1111/j.1469-8137.2012.04193.x

Shinozawa, A., Otake, R., Takezawa, D., Umezawa, T., Komatsu, K., Tanaka, K., et al. (2019). SnRK2 protein kinases represent an ancient system in plants for adaptation to a terrestrial environment. Commun. Biol. 2, 1-13. doi: 10.1038/ s42003-019-0281-1

Soma, F., Takahashi, F., Suzuki, T., Shinozaki, K., and Yamaguchi-Shinozaki, K. (2020). Plant Raf-like kinases regulate the mRNA population upstream of ABA-unresponsive SnRK2 kinases under drought stress. Nat. Commun. 11, 112. doi: 10.1038/s41467-020-15239-3

Soni, D. K., Ranjan, S., Singh, R., Khare, P. B., Pathre, U. V., and Shirke, P. A. (2012). Photosynthetic characteristics and the response of stomata to environmental determinants and ABA in Selaginella bryopteris, a resurrection spike moss species. Plant Sci. 191, 43-52. doi: 10.1016/j.plantsci.2012.04.011

Soon, F. F., Ng, L. M., Zhou, X. E., West, G. M., Kovach, A., Tan, M. H., et al. (2012). Molecular mimicry regulates ABA signaling by SnRK2 kinases and PP2C phosphatases. Science 335, 85-88. doi: 10.1126/science.1215106

Stevenson, S. R., Kamisugi, Y., Trinh, C. H., Schmutz, J., Jenkins, J. W., Grimwood, J., et al. (2016). Genetic analysis of Physcomitrella patens identifies ABSCISIC ACID NON-RESPONSIVE, a regulator of aba responses unique to basal land plants and required for desiccation tolerance. Plant Cell 28, 1310-1327. doi: $10.1105 /$ tpc. 16.00091

Sulochana, S. B., and Arumugam, M. (2016). Influence of abscisic acid on growth, biomass and lipid yield of Scenedesmus quadricauda under nitrogen starved condition. Biores. Technol. 213, 198-203. doi: 10.1016/j.biortech.2016.02.078

Sun, Y., Harpazi, B., Wijerathna-Yapa, A., Merilo, E., de Vries, J., Michaeli, D., et al. (2019). A ligand-independent origin of abscisic acid perception. Proc. Natl. Acad. Sci. U. S. A. 116, 24892-24899. doi: 10.1073/pnas.1914480116

Szostkiewicz, I., Richter, K., Kepka, M., Demmel, S., Ma, Y., Korte, A., et al. (2010). Closely related receptor complexes differ in their ABA selectivity and sensitivity. Plant J. 61, 25-35. doi: 10.1111/j.1365-313X.2009.04025.x

Takahashi, Y., Zhang, J., Hsu, P. K., Ceciliato, P. H. O., Zhang, L., Dubeaux, G., et al. (2020). MAP3Kinase-dependent SnRK2-kinase activation is required for abscisic acid signal transduction and rapid osmotic stress response. Nat. Commun. 11, 12. doi: 10.1038/s41467-019-13875-y

Takezawa, D., Komatsu, K., and Sakata, Y. (2011). ABA in bryophytes: how a universal growth regulator in life became a plant hormone? J. Plant Res. 124, 437-453. doi: 10.1007/s10265-011-0410-5

Taylor, I., Linforth, R., Al-Naieb, R., Bowman, W., and Marples, B. (1988). The wilty tomato mutants flacca and sitiens are impaired in the oxidation of ABAaldehyde to ABA. Plant Cell Environ. 11, 739-745. doi: 10.1111/j.13653040.1988.tb01158.x

Tietz, A., and Kasprik, W. (1986). Identification of abscisic acid in a green alga. Biochem. und Physiol. der Pflanzen 181, 269-274. doi: 10.1016/S0015-3796(86) 80093-2

Tietz, A., Ruttkowski, U., Kohler, R., and Kasprik, W. (1989). Further investigations on the occurrence and the effects of abscisic acid in algae. Biochem. und Physiol. der Pflanzen 184, 259-266. doi: 10.1016/S0015-3796(89)80011-3

Tougane, K., Komatsu, K., Bhyan, S. B., Sakata, Y., Ishizaki, K., Yamato, K. T., et al. (2010). Evolutionarily conserved regulatory mechanisms of abscisic acid signaling in land plants: characterization of ABSCISIC ACID INSENSITIVE1-like type 2C protein phosphatase in the liverwort Marchantia polymorpha. Plant Physiol. 152, 1529-1543. doi: 10.1104/pp.110.153387

Ullrich, W. R., and Kunz, G. (1984). Effect of abscisic acid on nitrate uptake, respiration and photosynthesis in green algae. Plant Sci. Lett. 37, 9-14. doi: 10.1016/0304-4211(84)90195-0

Umezawa, T., Sugiyama, N., Mizoguchi, M., Hayashi, S., Myouga, F., YamaguchiShinozaki, K., et al. (2009). Type 2C protein phosphatases directly regulate abscisic acid-activated protein kinases in Arabidopsis. Proc. Natl. Acad. Sci. U. S. A. 106, 17588-17593. doi: 10.1073/pnas.0907095106
Umezawa, T., Nakashima, K., Miyakawa, T., Kuromori, T., Tanokura, M., Shinozaki, K., et al. (2010). Molecular basis of the core regulatory network in ABA responses: sensing, signaling and transport. Plant Cell Physiol. 51, 18211839. doi: $10.1093 / \mathrm{pcp} / \mathrm{pcq} 156$

Vaidya, A. S., Peterson, F. C., Yarmolinsky, D., Merilo, E., Verstraeten, I., Park, S.Y., et al. (2017). A rationally designed agonist defines subfamily IIIA abscisic acid receptors as critical targets for manipulating transpiration. ACS Chem. Biol. 12, 2842-2848. doi: 10.1021/acschembio.7b00650

Vaidya, A. S., Helander, J. D., Peterson, F. C., Elzinga, D., Dejonghe, W., Kaundal, A., et al. (2019). Dynamic control of plant water use using designed ABA receptor agonists. Science 366, eaaw8848. doi: 10.1126/science.aaw8848

Vlad, F., Rubio, S., Rodrigues, A., Sirichandra, C., Belin, C., Robert, N., et al. (2009). Protein phosphatases 2C regulate the activation of the Snf1-related kinase OST1 by abscisic acid in Arabidopsis. Plant Cell 21, 3170-3184. doi: 10.1105/tpc.109.069179

Vlad, F., Droillard, M. J., Valot, B., Khafif, M., Rodrigues, A., Brault, M., et al. (2010). Phospho-site mapping, genetic and in planta activation studies reveal key aspects of the different phosphorylation mechanisms involved in activation of SnRK2s. Plant J. 63, 778-790. doi: 10.1111/j.1365-313X.2010.04281.x

Wanless, I., Bryniak, N., and Fensom, D. (1973). The effect of some growthregulating compounds upon electroosmotic measurements, transcellular water flow, and $\mathrm{Na}, \mathrm{K}$, and $\mathrm{Cl}$ influx in Nitella flexilis. Can. J. Bot. 51, 1055-1070. doi: 10.1139/b73-130

Weiner, J. J., Peterson, F. C., Volkman, B. F., and Cutler, S. R. (2010). Structural and functional insights into core ABA signaling. Curr. Opin. Plant Biol. 13, 495-502. doi: 10.1016/j.pbi.2010.09.007

Weng, J. K., Ye, M., Li, B., and Noel, J. P. (2016). Co-evolution of hormone metabolism and signaling networks expands plant adaptive plasticity. Cell 166, 881-893. doi: 10.1016/j.cell.2016.06.027

Xue, T., Wang, D., Zhang, S., Ehlting, J., Ni, F., Jakab, S., et al. (2008). Genomewide and expression analysis of protein phosphatase $2 \mathrm{C}$ in rice and Arabidopsis. BMC Genomics 9, 550. doi: 10.1186/1471-2164-9-550

Yasumura, Y., Pierik, R., Kelly, S., Sakuta, M., Voesenek, L. A., and Harberd, N. P. (2015). An ancestral role for CONSTITUTIVE TRIPLE RESPONSE1 proteins in both ethylene and abscisic acid signaling. Plant Physiol. 169, 283-298. doi: 10.1104/pp.15.00233

Yin, P., Fan, H., Hao, Q., Yuan, X., Wu, D., Pang, Y., et al. (2009). Structural insights into the mechanism of abscisic acid signaling by PYL proteins. Nat. Struct. Mol. Biol. 16, 1230-1236. doi: 10.1038/nsmb.1730

Yoshida, K., Igarashi, E., Mukai, M., Hirata, K., and Miyamoto, K. (2003). Induction of tolerance to oxidative stress in the green alga, Chlamydomonas reinhardtii, by abscisic acid. Plant Cell Environ. 26, 451-457. doi: 10.1046/ j.1365-3040.2003.00976.x

Yoshida, K., Igarashi, E., Wakatsuki, E., Miyamoto, K., and Hirata, K. (2004). Mitigation of osmotic and salt stresses by abscisic acid through reduction of stress-derived oxidative damage in Chlamydomonas reinhardtii. Plant Sci. 167, 1335-1341. doi: 10.1016/j.plantsci.2004.07.002

Zhang, Y., Li, Q., Jiang, L., Kai, W., Liang, B., Wang, J., et al. (2018). Suppressing type $2 \mathrm{C}$ protein phosphatases alters fruit ripening and the stress response in tomato. Plant Cell Physiol. 59, 142-154. doi: 10.1093/pcp/pcx169

Conflict of Interest: The authors declare that the research was conducted in the absence of any commercial or financial relationships that could be construed as a potential conflict of interest.

Copyright $(2020$ Sun, Pri-Tal, Michaeli and Mosquna. This is an open-access article distributed under the terms of the Creative Commons Attribution License (CC BY). The use, distribution or reproduction in other forums is permitted, provided the original author(s) and the copyright owner(s) are credited and that the original publication in this journal is cited, in accordance with accepted academic practice. No use, distribution or reproduction is permitted which does not comply with these terms. 